\title{
O papel da polícia Judiciária no Brasil E SUA IMPORTÂNCIA PARA A ESTRUTURAÇÃo, MANUTENÇÃo, FORTALECIMENTO E EVOLUÇÃo DA DEMOCRACIA
}

\author{
Priscila de Castro busnello
}

Departamento de Polícia Federal

$\approx$

\begin{abstract}
RESUMO
O objetivo desse artigo é demonstrar a influência da atividade de Polícia Judiciária no Estado Democrático de Direito brasileiro, por meio de uma breve análise histórica e evolutiva. Foi a Revolução Francesa que representou o marco histórico dos direitos humanos e qualificou a polícia como uma instituição cidadã e garantidora desses direitos. No entanto, foi com a Constituição Federal de 1988, que a função de Polícia Judiciária, atribuída às Polícias Federal e Civis, passou a respaldar a manutenção e o fortalecimento das instituições democráticas no Estado de Direito Humanista.
\end{abstract}

Palavras-Chave: Polícia Judiciária. Democracia. Direitos Humanos

\section{INTROdUÇão: ANÁlise do TEMA SOB UM ENFOQUE MULTIDISCIPLINAR}

A breve reflexão a que me proponho no momento tem como ponto central a relevância do papel da Polícia Judiciária no Brasil e sua influência para a estruturação, manutenção, fortalecimento e evolução da democracia. Contudo, antes de abordar diretamente o tema, é preciso mencionar alguns aspectos que são fundamentais para a compreensão da questão, já que a essência do debate maduro pressupõe a demonstração dos fundamentos, das razões e dos caminhos que nos levam à conclusão.

Para que se possa realizar uma abordagem científica sobre determinado objeto, é indispensável a contextualização. Os eventos devem ser analisados por tempos e lugares, para que lhes sejam atribuídos adequadamente significação e valor. Os fatos, quando não imediatamente apresentados, são modificados pelos que os precedem e pela própria natureza dos homens, costumes e clima. 
A pesquisa científica no campo do Direito demanda prévio conhecimento sobre experiências e comportamentos humanos do passado, que são influenciados por infinitos aspectos e estudados pelas mais diversas áreas do conhecimento. Impossível estudar o Direito sem contextualizá-lo no tempo e espaço de uma sociedade. Além disso, nesse campo, a multidisciplinaridade é um instrumento necessário para o desenvolvimento do pensamento complexo, com a finalidade de possibilitar a coleta de dados, apreensão de ideias, compreensão, reflexão, construção do conhecimento e concepção de novas soluções viáveis para os problemas que surgem.

Porém, as abordagens multidisciplinares requerem adequada educação para a escolha, o tratamento e o uso da informação. É necessário saber globalizar as ideias, refletir e construir gradativamente novos conhecimentos, de modo a superar a mera reprodução de análises anteriores. Logo, a crença na possibilidade de se desenvolver estudos fragmentários e isolados está definitivamente superada.

Decisões políticas, fenômenos naturais e climáticos, catástrofes, comportamentos humanos ao redor do mundo, enfim, inumeráveis eventos influem na maneira de viver do homem, ora representando avanços em termos de desenvolvimento (individual e social), ora ensejando a total desorientação. São esses eventos que desafiam a capacidade humana de reação. Grandes catástrofes, acidentes naturais ou mesmo atos criminosos de grande repercussão abrem as portas para infinitos campos de análise. É a partir da vivência das crises, da apreciação e dos estudos técnicos interdisciplinares sobre os eventos do passado que se obtém a aprendizagem. E essa aprendizagem prática é o que possibilita o desenvolvimento de açôes preventivas para o futuro.

\section{A SOCIEDADE GLOBAL E O RISCO}

Com a seguinte manifestação, a bióloga Rachel Carson denuncia em sua obra "Primavera Silenciosa" (1962), a realidade da época e dá início ao poderoso movimento social que alterou o curso da história: "Pela primeira vez na história do mundo, agora todo ser humano está sujeito ao contato com substâncias químicas perigosas, desde o instante que é concebido até sua morte". (CARLSON, 2010, p. 29) 
Subjaz ao relato a denúncia de um grande problema que ainda hoje, após mais de 50 anos, não foi solucionado. Ao contrário, as discussões estão na ordem do dia e tornaram-se ainda mais complexas. Trata-se do conflito estabelecido entre o desenvolvimento tecnológico (substâncias químicas para controle do desenvolvimento de pragas na agricultura) e a preservação da vida humana (exposição do ser humano a substâncias perigosas, que lhe ameaçam a saúde e com implicações que não são dimensionadas).

No início do século $\mathrm{XX}$, duas grandes guerras que legaram ao homem as maiores marcas de catástrofes históricas inesquecíveis e cujas consequências alteraram substancialmente o rumo da humanidade. Em seguida, uma série de outras catástrofes, crises e tragédias desenhou o panorama sombrio do século XX e da primeira década do século XXI. Ulrich Beck aponta, com precisão ímpar, que, ao olhar para as singularidades históricas que abrangem tais calamidades, é possível constatar que, paulatinamente, houve verdadeira mudança substancial na maneira de observar, analisar, sentir e reagir do homem. Isso porque, nas palavras no referido autor, "todo o sofrimento, toda a miséria e toda a violência que seres humanos infligiram a seres humanos eram até então reservados à categoria dos "outros" - judeus, negros, mulheres, refugiados, dissidentes, comunistas, etc." (BECK, 2010, p. 7)

Nesse cenário, os observadores (que não pertenciam às categorias) estavam protegidos por fronteiras reais ou simbólicas, onde aparentemente não eram afetados e onde poderiam tranquilamente se recolher. Desde Chernobyl , a figura dos "outros" indubitavelmente deixou de existir, assim como a possibilidade de segregação das catástrofes, que foi eliminada pela invisível contaminação nuclear. De fato, o poder do átomo suprimiu as fronteiras do perigo hipotético e atingiu o conhecimento humano, por meio de uma catástrofe. $\mathrm{O}$ mundo passou a conhecer e admitir que uma contaminação nuclear perigosa equivale à admissão da inexistência de qualquer saída possível, para todas as regiões do planeta.

Os riscos e efeitos da modernização, que se precipitam sob a forma de ameaças à vida dos seres humanos, assumem significado novo e decisivo nos debates sociais e políticos, pois já não podem ser limitados geograficamente ou em função de grupos específicos, ou seja, a tendência globalizante faz surgir ameaças supranacionais e independentes de classes. 
O avanço da globalização sepultou de vez o fenômeno conhecido popularmente como NIMBY (not in my back yard), de modo a ampliar a responsabilidade e a repartição de riscos a um nível planetário. O chamado efeito bumerangue, que emerge da globalização, cedo ou tarde, produzirá o efeito de que os riscos alcancem inclusive aqueles que os produziram ou que lucraram com eles. Ele também faz com que todos, globalmente e por igual, arquem com os ônus.

A potencialização dos riscos converte a sociedade global em uma comunidade de perigos. As desigualdades internacionais e as interdependências do mercado global lançam os bairros pobres dos países periféricos às portas dos ricos centros industriais. As ameaças à vida passam pelas metamorfoses sociais do perigo. Os sistemas jurídicos, por sua vez, não dão conta das situações de fato.

\section{A SOCIEDAde do RisCo E A PROTEÇÃo PENAL}

Constata-se que houve uma ruptura do paradigma de proteção de bens individuais e sociais que repercutiu em diversas áreas do Direito, mas substancialmente no campo do Direito Penal e do Direito Processual Penal. Isso porque os chamados bens jurídicos menos individuais (transindividuais, metaindividuais ou interesses difusos) ingressaram no panorama mundial e penetraram o ambiente do Direito. Nesse sentido, a efetiva proteção dessa nova espécie de bens jurídicos deve ser garantida, inclusive, por intermédio da intervenção ativa do Estado.

No entanto, a intervenção Estatal efetiva e ampla pode ser algo extremamente difícil na prática, principalmente quando se trata de viabilizar a persecução penal no campo da prevenção de riscos. Insegurança é certamente a característica marcante de nossa era. A humanidade vivencia a era de temores e o medo é um sentimento conhecido. Neste cenário de medo, impera a tentativa constante de minimização dos riscos, seja com a racionalização individual dos perigos, que se traduz na contratação de seguros seja com a movimentação coletiva no sentido de atribuir responsabilidades por ações ou omissões, com uma feição criminosa.

1 NIMBY (not in my back yard ou "não em meu jardim") é um termo utilizado com conotação negativa para designar o egoísmo de coletividades locais em relação à instalação de algo negativo (como empresas poluidoras, construção de presídios, unidades de tratamento de lixo e dejetos, unidades de tratamento de toxicômanos, etc.) nas suas imediações, mas que poderiam ser toleradas por essa coletividade em qualquer outro lugar do planeta. 
Neste último caso, por vezes, exige-se do Estado uma postura firme de repressão que culmina com a edição descontrolada de leis, frutos do clamor de uma coletividade assustada. $\mathrm{Na}$ esfera da sociedade de risco atual, houve o incremento do chamado direito penal de risco, que nada mais é do que uma espécie de criminalização em âmbito prévio (SILVEIRA, 2003, pps 121-122). São, em geral, situações caracterizadas como de perigo abstrato, tentativa, punição de atos preparatórios e proteção de bens difusos.

A imputação de riscos coloca em discussão os limites de redução, ampliação e flexibilização dos princípios e garantias tradicionais. Contudo, a imputação de riscos há que ser considerada como uma medida globalizante viável de proteção dos interesses que são mais caros aos seres humanos, ou seja, a vida e a saúde. O homem é confrontado com inéditas realidades nas quais a criminalidade ganhou novos contornos. A globalização expõe e fragiliza, de modo que o Estado deve se adaptar ao novo ambiente e utilizar instrumentos eficientes de controle da criminalidade.

\section{O VALOR LIBERDADE E OS DIREITOS DO HOMEM: O Surgimento da Polícia Judiciária na perspectiva DE PROTEÇÃO DOS DIREITOS INDIVIDUAIS}

A ideia de liberdade emerge com força total no século XVIII. Essa liberdade está atrelada à ascensão da classe burguesa na França, que passa a ter importância nas transformações políticas, sociais, econômicas e culturais. $\mathrm{O}$ homem finalmente começou a compreender seu papel na história.

A Revolução Francesa (1789) foi fortemente influenciada pela Revolução Americana (1776) e pelas liberdades inglesas. Esses movimentos representaram o início do processo de conscientização humana, uma verdadeira revolução do pensamento. Nesse período, começa a ser constituído um saber científico que toma o homem como objeto de conhecimento, e não mais a natureza. Apenas nessa época é que o espírito científico pensa, pela primeira vez, em aplicar ao próprio homem os métodos até então utilizados na área física ou da biologia (LAPLANTINE, 2003, p. 7).

A Declaração de Independência dos Estados Unidos enalteceu os direitos de revolução e também os direitos individuais, ideias que se difundiram pelo país e internacionalmente. Está expresso na Declaração: "Conside- 
ramos estas verdades como evidentes, que todos os homens são criados iguais, que eles são dotados pelo Criador de certos Direitos inalienáveis, dentre os quais estão a Vida, Liberdade e a busca da Felicidade".2 (tradução nossa).

$\mathrm{Na}$ França, o movimento teve como objetivo derrubar o ancien régime, o que ocorreu em 1789 com a Revolução Francesa. Durante o período mais agressivo da Revolução foi criado, difundido e exaustivamente utilizado o célebre lema Liberdade, Igualdade, Fraternidade. E curiosamente foi nesse contexto liberal da Revolução Francesa que começou a se resolver a antiga contradição entre polícia e liberdade.

Exatamente nesse momento histórico foram concebidos os quadros de uma polícia cidadã a serviço dos direitos do homem, conforme será esclarecido nos próximos tópicos. Contudo, como bem observado por Jean-Marc Berlière (2013), contrariamente aos países que adotam o modelo de Direito anglo-saxão, a história da polícia na França ${ }^{3}$ é um buraco negro na historiografia. Há algumas razões para isso ${ }^{4}$.

A primeira e mais evidente é a falta de interesse da comunidade científica por um objeto "politicamente incorreto", "amargo", ligado a uma ideia de "repressão", de "fascismo", etc. Essa argumentação preconceituosa, simplista e reducionista cede sob o argumento de que a polícia pode sim servir à opressão em um regime totalitário, mas também atuar na defesa das liberdades em um Estado democrático.

A segunda razão pode ser atribuída ao medo causado pela popularização da figura monstruosa do policial, influenciada pelos leitores de Balzac, Victor Hugo e George Orwell.

O terceiro motivo, de ordem empírica, é a dificuldade de acesso a arquivos e documentos históricos. Dificuldade que impediu a construção de um conhecimento racional, sem paixões e nem julgamentos, sobre a história da instituição que ocupou e ocupa papéis essenciais e delicados.

2 Trecho original "We hold these truths to be self-evident, that all men are created equal, that they are endowed by their Creator with certain unalienable Rights, that among these are Life, Liberty and the pursuit of Happiness." apud http://www.archives.gov/exhibits/charters/declaration_transcript.html, acesso em 03.10.2015.

3 E extensivamente os países que adotam o modelo de Direito Romano.

4 Além disso, se o tema não despertou o interesse da comunidade científica, ao contrário, foi consagrada como a maior fonte de inspiração para a literatura jornalística. 
Não obstante a existência de material escasso, registros de tempos remotos indicam que a polícia tem suas origens nas primeiras cidades-estados que descobriram rapidamente a necessidade de regras para organizar a vida na cidade e a própria vida em conjunto.

Etimologicamente, a palavra "polícia" encontra sua origem na ligação entre "polícia e cidade", mas com uma acepção ampla. Do grego politeia que designava na Grécia Antiga tudo o que se reportava à cidade e a seu governo, portanto, em um sentido mais amplo "governo da cidade" (regras de higiene, ordem pública, moral e bons costumes, religião, etc.).

Nicolas Delamarre, em sua obra "Tratado da Polícia”, do início do século XVIII, atribuiu à polícia nada menos do que a ideia de "felicidade do homem":

O único objeto da polícia consiste em conduzir o homem à mais perfeita felicidade que ele possa desfrutar nessa vida... Ela tem por objeto assegurar aos homens os bens da alma, os bens do corpo e o que se costuma chamar de fortuna (tradução nossa). (apud BERLIËRE, 2013, p. 12)

Mas, conforme já mencionado, foi a Revolução Francesa que representou o verdadeiro marco histórico, pois qualificou e situou a polícia como uma instituição cidadã, a serviço dos direitos do homem. Com a Declaração de Direitos do Homem e do Cidadão, de 26 de agosto de 1789, são estabelecidos os princípios essenciais, e a aparente antinomia entre polícia, ordem e liberdade é resolvida da seguinte forma: se a polícia restringe e limita a liberdade (que tiveram o cuidado de definir no artigo 4 como "tudo o que não prejudica os outros"), é para defender os direitos naturais e imprescritíveis do homem (enumerados no artigo 2 como: "(...) liberdade, a propriedade, a segurança, a resistência à opressão”). Dessa forma, a Força Pública, prevista no artigo 12 é instituída para "a garantia dos direitos do homem" e "para o bem de todos e não para a utilidade particular daqueles a quem ela é conferida”.

Então a função da polícia passou a ser compreendida àquela época da seguinte forma: não há governo que possa manter o direito dos cidadãos sem uma polícia severa; mas a diferença entre um regime livre e um regime tirano é que no primeiro, a polícia é exercida em relação à minoria que se opõe ao bem geral e em relação aos abusos e negligências da autoridade, enquanto no segundo, a polícia do Estado é exercida contra os infelizes entregues à injustiça e à impunidade do poder. 
A partir de 1789, diversos textos legislativos franceses passaram a tratar da atividade da polícia. Merece destaque, como obra essencial em matéria de definição, de precisão e de racionalização, o Código dos Delitos e das Penas 5 , de 25 de outubro de 1795, cujo texto serviu de base a todos os regimes posteriores:

CÓDIGO DOS DELITOS E DAS PENAS DE 3 BRUMÁRIO, ANO 4 (25 de outubro de 1795) Contendo as Leis relativas à instrução dos casos criminais.

\section{DISPOSIÇÕES PRELIMINARES}

ARTIGO 15

A repressão aos delitos exige a ação de duas autoridades distintas e incompativeis, a da polícia e a da justiça.

A ação da polícia precede essencialmente a da justiça.

$$
\text { LIVRO I - DA POLÍCIA }
$$

ARTIGO 16

A policia é instituida para manter a ordem pública, a liberdade, a propriedade, a segurança individual.

ARTIGO 17

Seu caráter principal é a vigilância.

A sociedade, considerada em massa, éo objeto de sua atenção.

ARTIGO 18

Ela se divide em policia administrativa e polícia judiciária.

ARTIGO 19

A polícia administrativa tem por objeto a manutenção habitual da ordem pública em cada lugar e em cada parte da administração geral.

Ela tende principalmente a prevenir os delitos.

As leis que lhe dizem respeito são parte do código das administrações civis. ARTIGO 20

A policia judiciária investiga os delitos que a policia administrativa não pôde impedir de serem cometidos, coleta as provas e encaminha os autores aos tribunais encarregados pela lei de puni-los. (tradução nossa). ${ }^{6}$

$5 \mathrm{http}: / /$ ledroitcriminel.free.fr/la_legislation_criminelle/anciens_textes/code_delits_et_ peines_1795/ code_delits_et_peines_1795_1.htm, acesso em 03.10.2015.

6 Versão original:

CODE DES DÉLITS ET DES PEINES DU 3 BRUMAIRE, AN 4 (25 octobre 1795) Contenant les 
Tamanha precisão e realismo do conceito de polícia judiciária também devem ser compreendidos de acordo com os acontecimentos da época. Essa definição da atividade de polícia judiciária é uma consequência direta da separação de poderes prevista pela Lei 16-24 de agosto de 1790. A Revolução Francesa, a Declaração de Direitos do Homem e do Cidadão e a Constituição de 1791 foram os fundamentos para o estabelecimento de novas bases da própria justiça francesa. Nenhuma outra reforma pode ser comparada a essa do final do século XVIII?.

A justiça do ancien régime era extremamente complicada, o que a tornava praticamente inacessível aos cidadãos. Era admitida a tortura no próprio âmbito judicial. Após a Revolução, houve a consagração da separação dos poderes, em 1790, e o princípio da legalidade foi reconhecido em 1791, pela primeira Constituição escrita.

Na concepção dos revolucionários, a Justiça deveria ser simplificada e, radicalmente diferente do modelo anterior, deveria estar acessível de forma igualitária e gratuita e muito mais próxima dos cidadãos. Para isso, os juízes passaram a ser eleitos (independência da magistratura), os debates passaram a ser públicos, bem como foi previsto o direito de defesa e estabelecido o júri popular especificamente para a matéria criminal.

Enfim, naquele momento histórico do final do século XVIII, foram delineadas e construídas as bases da justiça moderna, muito mais humana e transparente. Consequentemente, foram estabelecidas as bases sólidas do

Lois relatives à l'instruction des affaires criminelles DISPOSITIONS PRÉLIMINAIRES

ARTICLE 15 - La répression des délits exige l'action de deux autorités distinctes et incompatibles, celle de la police et celle de la justice.

L'action de la police précéde essentiellement celle de la justice.

LIVRE I - DE LA POLICE

ARTICLE 16 - La police est instituée pour maintenir l'ordre public, la liberté, la propriété, la sûreté individuelle.

ARTICLE 17 - Son caractère principal est la vigilance.

La société, considérée en masse, est l'objet de sa sollicitude.

ARTICLE 18 - Elle se divise en police administrative et en police judiciaire.

ARTICLE 19 - La police administrative a pour objet le maintien habituel de l'ordre public dans chaque lieu et dans chaque partie de l'administration générale.

Elle tend principalement à prévenir les délits.

Les lois qui la concernent font partie du code des administrations civiles.

ARTICLE 20 - La police judiciaire recherche les délits que la police administrative n'a pu empêcher de commettre, en rassemble les preuves, et en livre les auteurs aux tribunaux chargés par la loi de les punir.

7 http://www.justice.gouv.fr/histoire-et-patrimoine-10050/la-justice-dans-lhistoire-10288/loeuvrerevolutionnaire-les-fondements-de-la-justice-actuelle-1 1909.html, acesso em 03.10.2015. 
atual modelo de polícia judiciária cidadã. Tudo para concretizar o modelo de Estado que reconhece, valoriza e garante os direitos do homem.

\section{A atividade de Polícia Judiciária no Brasil}

A atividade de Polícia Judiciária no Brasil está prevista exclusivamente no Capítulo III (Da Segurança Pública), do Título V (Da Defesa do Estado e Das Instituições Democráticas) da Constituição Federal de 1988 $\mathrm{CF} / 88$, em dois momentos, quando trata das atribuições da Polícia Federal e quando dispõe sobre as atribuições das Polícias Civis (artigo 144 da CF/88):

Art. 144. A segurança pública, dever do Estado, direito e responsabilidade de todos, é exercida para a preservação da ordem pública e da incolumidade das pessoas e do patrimônio, através dos seguintes órgãos:

I-policia federal;

II - policia rodoviária federal;

III - polícia ferroviária federal;

IV-policias civis;

$V$-polícias militares e corpos de bombeiros militares.

$\$ 1^{\circ}$ A policia federal, instituida por lei como órgão permanente, organizado e mantido pela União e estruturado em carreira, destina-se a:

I - apurar infraçôes penais contra a ordem politica e social ou em detrimento de bens, serviços e interesses da União ou de suas entidades autárquicas e empresas públicas, assim como outras infrações cuja prática tenha repercussão interestadual ou internacional e exija repressão uniforme, segundo se dispuser em lei;

II - prevenir e reprimir o tráfico ilícito de entorpecentes e drogas afins, o contrabando e o descaminho, sem prejuizo da ação fazendária e de outros órgãos públicos nas respectivas áreas de competência;

III - exercer as funções de policia maritima, aeroportuária e de fronteiras;

$I V$ - exercer, com exclusividade, as funções de polícia judiciária da União.

\section{(...)}

$\$ 4^{\circ}$ Às policias civis, dirigidas por delegados de polícia de carreira, incumbem, ressalvada a competência da União, as funções de policia judiciária e a apuração de infrações penais, exceto as militares. 
Portanto, em nenhum momento, a CF/88 deixa espaço para dúvidas ou interpretações em relação aos órgãos que atribuiu competência para o exercício das funções de Polícia Judiciária: a) Polícia Federal; e b) Polícias Civis dos Estados (de forma residual em relação à competência da União e com exceção de infrações militares). Outras atribuições relacionadas à segurança pública como, por exemplo, a preservação da ordem pública ou o patrulhamento ostensivo de rodovias foram conferidas às diversas polícias.

No entanto, o exercício da nobre função de Polícia Judiciária não é mera opção, mas sim um dever constitucional das Polícias Federal e Civis, expressamente relacionado à defesa do Estado e das instituições democráticas.

\section{A Constituição Federal de 1988 e a dignidade HUMANA}

Desde o final do século XX, é possível notar que houve a revalorização do direito como instrumento de harmonização da convivência, de realização da justiça e de garantia da paz. Profundas inovações começaram a se definir com o fim da II Guerra Mundial, e a Declaração Universal dos Direitos Humanos de 1948 marca o início da nova fase na história da humanidade. Em seu preâmbulo é expressamente afirmado o liame entre direitos fundamentais e dignidade humana ${ }^{8}$ :

Considerando que o reconhecimento da dignidade inerente a todos os membros da familia humana e de seus direitos iguais e inalienáveis é o fundamento da liberdade, da justiça e da paz no mundo,

Considerando que o desprezo e o desrespeito pelos direitos humanos resultaram em atos bárbaros que ultrajaram a consciência da Humanidade e que o advento de um mundo em que os homens gozem de liberdade de palavra, de crença e da liberdade de viverem a salvo do temor e da necessidade foi proclamado como a mais alta aspiração do homem comum,

Considerando essencial que os direitos humanos sejam protegidos pelo Estado de Direito, para que o homem não seja compelido, como último recurso, à rebelião contra tirania e a opressão,

Considerando essencial promover o desenvolvimento de relaçôes amistosas entre as naçôes,

8 Resolução 217 A (III) da Assembléia Geral das Nações Unidas em 10 de dezembro de 1948. Declaração Universal dos Direitos Humanos. Disponível em http://portal.mj.gov.br/sedh/ct/legis_ intern/ddh_bib_inter_universal.htm, acesso em 24.05.2015. 
Considerando que os povos das Nações Unidas reafirmaram, na Carta, sua fé nos direitos humanos fundamentais, na dignidade e no valor da pessoa humana e na igualdade de direitos dos homens e das mulheres, e que decidiram promover o progresso social e melhores condiçôes de vida em uma liberdade mais ampla,

Considerando que os Estados-Membros se comprometeram a desenvolver, em cooperação com as Nações Unidas, o respeito universal aos direitos humanos e liberdades fundamentais e a observância desses direitos e liberdades,

Considerando que uma compreensão comum desses direitos e liberdades é da mais alta importância para o pleno cumprimento desse compromisso.

A aproximação das ideias de constitucionalismo e de democracia produziu nova forma de organização política, o Estado democrático de direito, que se consolida no último quarto do século XX e tem como característica central a subordinação da legalidade a uma Constituição rígida. A democracia é a alma desse Estado de Direito e ultrapassa a noção de governo da maioria, pois se trata de governo para todos. Nesse contexto, a Constituição Federal de 1988 marca o início do processo de redemocratização do Brasil.

Flávia Piovesan $(2011$, p. 76) observa que, a partir da Carta de 1988, os direitos humanos ganham relevo extraordinário, pois trata-se do documento mais abrangente e pormenorizado sobre os direitos humanos jamais adotado no Brasil. Logo no artigo $1^{\circ}$, a Constituição Federal de 1988 já declara que a República Federativa do Brasil se constitui em Estado Democrático de Direito e tem como fundamentos: a soberania, a cidadania, a dignidade da pessoa humana, os valores sociais do trabalho e da livre iniciativa e o pluralismo político.

O reconhecimento da dignidade humana, no sentido hegeliano de "sê uma pessoa e respeita os outros como pessoas" (HEGEL, 1997, p. 40), como fundamento da República Federativa do Brasil representou verdadeira mudança de paradigma na forma de pensar, criar, interpretar e concretizar o Direito. Dificílimo reduzir em apertadas linhas a imponência do significado da dignidade da pessoa humana. Mas as dificuldades relacionadas ao tema superam o campo da filosofia, pois a compreensão exige uma visão holística. Nas últimas décadas, a dignidade da pessoa humana passou a ocupar o centro das grandes discussões travadas no mundo Ocidental. Sua magnitude no 
Direito atual extrapola o âmbito dos Estados e até mesmo o plano internacional, pois assume cada vez maior e mais acentuada importância na esfera transnacional.

\section{O USO LEGítimo DA FORÇA NO EXERCício DA ATIVIDADE DE POLÍCIA JUDICIÁRIA}

Para garantir a dignidade humana, em sua plenitude, a manutenção da paz e da harmonia social, é possível o uso legítimo da força no atual Estado Democrático de Direito. A criminalização e o uso da força estatal contra condutas atentatórias a bens jurídicos são formas efetivas que o Estado dispõe para a concretização dos direitos fundamentais nas suas diversas dimensões. De acordo com a doutrina, exceto nos casos em que atua como protetora dos direitos nos conflitos internos da sociedade (em suas relações horizontais de poder), é da essência da atividade policial resultar em ofensa a direitos, liberdades e garantias (embora legítima no caso concreto, em virtude do reconhecimento de que os direitos não são ilimitados).

Em uma análise sistemática, não há ofensa a direitos se a atuação policial está legitimada, ou seja, há respaldo fático, legal e jurídico. Contudo, a atuação policial, principalmente no exercício da função de polícia judiciária, está submetida a uma tríplice dimensão do princípio da legalidade.

Em primeiro lugar, a legalidade significa obrigação de agir. Conforme destacado, a Constituição Federal de 1988 atribuiu competência às Polícias Federal e Civis para o exercício das funções de Polícia Judiciária, portanto, trata-se de um dever.

A legalidade significa também limite da atuação policial. E esse limite deve ser observado tanto para o mínimo quanto para o máximo, ou seja, verificada a obrigação de agir no caso concreto, devem ser adotadas as medidas mínimas necessárias para coleta das provas de autoria (ou não autoria) e materialidade de eventual crime ou efetiva comprovação de que o crime não ocorreu. Nesse sentido, constatado no caso concreto que a medida de investigação necessária está resguardada pelo princípio de reserva de jurisdição, deve ser viabilizada a devida comunicação ao juiz competente, com representação pela autorização judicial para execução da medida. 
E, finalmente, como garantia, respaldo e legitimidade de atuação, já que a atuação de acordo com a lei é (em princípio) legítima. A lei funciona, nesse sentido, como uma autorização para agir de determinada forma, direcionando a atividade policial. O respaldo legal no Direito Positivo (para a atuação ou não atuação) é o mínimo a ser observado no exercício da atividade de polícia judiciária. Mas, na prática, as situações da vida nem sempre estão bem descritas ou reguladas pela lei.

Também podem acontecer mudanças nas circunstâncias, com a necessidade de correta adequação do sentido da lei. Portanto, é importante o conhecimento da própria norma e do ordenamento jurídico.

\section{Conclusão}

O papel da Polícia Judiciária no Brasil só pode ser bem compreendido por meio de uma análise multidisciplinar. Aliás, toda pesquisa científica séria no campo do Direito demanda o prévio conhecimento do objeto sob diversos prismas.

Além disso, é preciso estar preparado e devidamente educado para contextualizar os fatos no tempo e no espaço de uma sociedade. É insuficiente e temerária a mera tradução de leis e a comparação vazia entre normas que, descontextualizadas, não possuem o menor valor e tampouco servem para produzir novos conhecimentos, isso quando não representam apenas reproduções de análises anteriores.

O fenômeno da globalização possibilitou infinitos avanços tecnológicos, agilizou as relaçóes humanas e tornou as distâncias físicas praticamente insignificantes. Por outro lado, viabilizou inúmeros efeitos negativos e perversos. Diversas formas de ameaças à vida dos seres humanos já não podem ser contidas e limitadas geograficamente ou em função de grupos específicos, ou seja, a tendência globalizante faz surgir ameaças supranacionais e independentes de classes, de modo a ampliar a responsabilidade e a repartição de riscos a um nível planetário.

Nesse cenário global, a atividade de polícia judiciária passa por uma adaptação, que decorre diretamente da própria evolução histórica dos direitos do homem e da agilidade imposta pela globalização. Essa atividade de 
polícia judiciária, mais do que qualquer outra no Estado Democrático de Direito, está se tornando cada vez mais técnica e mais dependente de um esforço simultâneo e colaborativo de polícias judiciárias de outros países.

Mas, antes de avaliar esse aspecto, é preciso observar que o próprio reconhecimento e a devida proteção dos direitos humanos no Brasil, para ser efetiva, depende, num primeiro momento, de um alinhamento mínimo de proteção dos direitos humanos em nível mundial, pois a ausência em determinadas partes do mundo atrai os violadores, que ficam livres para praticar suas transgressões com consequências negativas de nível planetário, mas fortalecidos por um manto protetor de um Estado enfraquecido ou até mesmo leniente. E, num segundo momento, é necessário estabelecer um nível mínimo de repressão maciça, por meio de forças estatais legitimamente constituídas para a repressão efetiva das violações aos direitos humanos, mormente quando se materializam em atos criminosos praticados em seus territórios.

As noções modernas de direitos humanos, polícia judiciária e de poder judiciário estão intimamente ligadas, pois apresentam origem histórica comum. Foram todas concebidas no contexto revolucionário de 1789. A Revolução Francesa, baseada nos ideais de "liberdade, igualdade e fraternidade", ensejou não apenas o fim do ancien régime, mas sim o início de uma mudança radical, que foi concretizada pela concepção e construção de um modelo de Estado sólido, sustentado pelos pilares da democracia, da cidadania e principalmente do respeito à condição humana. Foi a ruptura com o regime opressor que deu ensejo ao nascimento de uma nova cultura, baseada nas ideias iluministas, que foram difundidas mundialmente por meio da famosa Declaração de Direitos do Homem e do Cidadão, de 26 de agosto de 1789.

A dignidade humana e a legalidade são as bases dessa concepção. Para fomentá-la e preservá-la, foi necessário construir um sólido modelo estatal, inicialmente com a separação dos poderes, que foi expressamente estabelecida por uma Lei Francesa de 1790. O princípio da legalidade foi expressamente previsto na primeira Constituição Escrita da França, em 1791. De modo que as concepções da Revolução Francesa foram gradativamente integrando o novo sistema. Nesse contexto, foram instituídas as bases sólidas do atual modelo de polícia judiciária cidadã. 
A aparente antinomia entre polícia, ordem e liberdade foi superada, pois a polícia restringe e limita a liberdade para defender os direitos naturais e imprescritíveis do homem (a liberdade, a propriedade, a segurança, a resistência à opressão). Dessa forma, a Força Pública, expressamente prevista no artigo 12 da Declaração de Direitos do Homem e do Cidadão, é concebida e instituída para "a garantia dos direitos do homem" e "para o bem de todos, e não para a utilidade particular daqueles a quem ela é conferida”.

Mas os ideais iluministas do final do século XVIII só foram retomados com força total em outro momento histórico, em meados do século XX, após as duas Grandes Guerras, que legaram aos homens as maiores marcas de catástrofes históricas inesquecíveis e cujas consequências alteraram substancialmente o rumo da humanidade. O contato com as catástrofes das Guerras traumatizou o mundo. O conhecimento sobre a potencialidade dos eventos nocivos, que antes não passavam de meras hipóteses no imaginário de algumas pessoas, ensejou a adoção de providências em nível global, para evitar os riscos de uma nova guerra.

A Declaração Universal dos Direitos Humano,s de 1948, marca o início dessa nova fase na história da humanidade. Em seu preâmbulo é estabelecida a ligação entre direitos fundamentais e dignidade humana. Nesse ambiente, os direitos do homem, a democracia e a paz emergem como conceitos necessários e inter-relacionados. A democracia é o ambiente propício para a manutenção da paz e ela só existe quando os direitos do homem são protegidos e reconhecidos?.

No Brasil, esses três conceitos foram consagrados pela Constituição Federal de 1988, conhecida como Constituição Cidadã. O artigo $1^{\circ}$ da CF/88 estabelece que a República Federativa do Brasil se constitui em Estado Democrático de Direito e tem como fundamentos: a soberania, a cidadania, a dignidade da pessoa humana, os valores sociais do trabalho e da livre iniciativa e o pluralismo político.

A defesa da paz está expressamente prevista no artigo 4o da CF/88, como um dos princípios que regem a República Federativa do Brasil nas suas

9 Essa relação entre direitos do homem, democracia e paz como três momentos necessários do mesmo movimento histórico também foi estabelecida por Norberto Bobbio da seguinte forma: sem direitos do homem reconhecidos e protegidos, não há democracia; sem democracia, não existem as condições mínimas para a solução pacífica dos conflitos (BOBBIO, Norberto. A era dos direitos. Rio de Janeiro: Elsevier, 2004, p. 1). 
relações internacionais. $\mathrm{E}$ os direitos e garantias fundamentais tornaram-se objeto de todo o Título II da CF/88. Nesse contexto, os direitos humanos foram evidenciados, pois pela primeira vez receberam proteção abrangente $\mathrm{e}$ pormenorizada no Brasil.

A dignidade da pessoa humana, expressamente reconhecida como fundamento do Estado Democrático de Direito, merece destaque, pois aliada aos direitos e garantias fundamentais confere um suporte axiológico peculiar a todo o sistema jurídico. O conteúdo valorativo da dignidade da pessoa humana, esclarecido pelas normas de Direitos Fundamentais, irriga as demais normas e instituições constitucionais, que foram concebidas justamente para assegurar condições mínimas de realização do ser humano.

A função de polícia judiciária é expressamente prevista na $\mathrm{CF} / 88$, justamente no Título V, que trata da defesa do Estado e das Instituiçóes Democráticas. Trata-se de função pública, da maior relevância que, concebida para a manutenção da democracia e da paz e para a preservação dos direitos humanos, foi expressamente atribuída a duas das polícias constitucionalmente previstas, Polícia Federal e Polícias Civis dos Estados (de forma residual em relação à competência da União e com exceção de infrações militares).

Portanto, seja em razão da relevância decorrente da vinculação com a defesa do Estado e das Instituições Democráticas, seja em função da atribuição constitucional com exclusividade, a função de Polícia Judiciária é um dever, um munus publico das Instituiçóes Policiais (Federal e Civis) perante a sociedade, de modo que o seu enfraquecimento atinge diretamente o Estado Democrático de Direito e a própria dignidade humana.

Dessa forma, quando se contextualiza a função de Polícia Judiciária, conclui-se que as forças policiais democráticas e cidadãs, legitimamente constituídas para essa finalidade, fazem parte de um Estado Democrático e legítimo.

As diretrizes da atividade policial devem também estar alinhadas com os valores fundamentais da sociedade.

Isso porque a apreciação sobre a sua natureza demanda uma análise global e recíproca sobre sociedade, Estado e governo, de modo que os pesquisadores consideram atualmente uma tríplice natureza do apare- 
lho policial: como um instrumento de poder, como um serviço público e como uma profissão.

Quando se menciona instrumento do poder, certamente refere-se ao poder democrático legítimo, pois é a atuação eficiente, precisa, justa e necessária do aparelho policial que fortalece e legitima a democracia. Por outro lado, a atuação como instrumento de poder é legitimada pela própria democracia.

Na qualidade de serviço público, deve ser ressaltado o aspecto da cidadania. O destinatário desse serviço é o próprio povo, a sociedade como um todo, que, organizada e submetida à lei, precisa de um aparato Estatal harmônico, eficiente e adequado, para garantir os direitos do homem contra violações injustas.

Por fim, no que diz respeito aos aspectos da profissão, é necessário ressaltar que se trata na realidade de uma verdadeira vocação profissional, que deve ser exercida com responsabilidade e com a devida consciência sobre o sistema de direitos e garantias do homem.

Priscila de Castro busnello

Delegada de Polícia Federal. Ex-Advogada da União. Especialista em Gestão da Segurança da Informação e Comunicações pela UNB/DF. Mestre e Doutoranda em Direito Processual Penal pela PUC/SP.

E-MAIL: PRISCILABUSNELLO@GMAIL.COM

\section{The role of the Judicial Police in Brazil}

\section{ABSTRACT}

The aim of this article is to demonstrate the influence of the Judicial Police activity in the Brazilian Democratic State, through a brief historical and evolutionary analysis. It was the French Revolution which represented the historic landmark of human rights and called the police as a civilian institution and guarantor of those rights. However, it was with the 1988 Federal Constitution, that the Judicial Police function, attributed to Federal and Civil Police, came to support the maintenance and strengthening of democratic institutions in the State of Humanist Law.

KEYwORDS: Judicial Police. Democracy. Human Rights. 


\title{
El Papel de la Policía Judicial en Brasil
}

\begin{abstract}
RESUMEN
El objetivo de este artículo es demostrar la influencia de la actividad de la Policía Judicial en el Estado democrático de derecho brasileño, a través de un breve análisis histórico y evolutivo. Fue la Revolución Francesa, que representaba el hito histórico de los derechos humanos y llamó a la policía como una institución civil y garante de esos derechos. Sin embargo, fue con la Constitución Federal 1988, que la función de Policía Judicial, que se atribuye a la Federal y la Policía Civil, que vino a apoyar el mantenimiento y fortalecimiento de las instituciones democráticas en el Estado de Derecho Humanista.
\end{abstract}

Palabras Clave: Policía Judicial. Democracia. Derechos humanos.

\section{REFERENCIAS}

BECK, Ulrich. Sociedade de risco - rumo a uma outra modernidade. São Paulo: editora 34, 2010.

BOBBIO, Norberto. A era dos direitos. Rio de Janeiro: Elsevier, 2004.

CARSON, Rachel. Primavera Silenciosa. São Paulo: Editora Gaia, 2010.

HEGEL, Georg Wilhelm Friedrich. Princípios da Filosofia do Direito. São Paulo: Martins Fontes, 1997.

LAPLANTINE, François. Aprender antropologia. São Paulo: Brasiliense, 2003.

MONJARDET, Dominique apud BERLIÈRE Jean-Marc et LÉVI René. Histoire des polices en France-de l'ancien regime à nos jours. Paris: Nouveau monde éditions, 2013.

PIOVESAN, Flávia. Direitos humanos e o direito constitucional internacional. 12. ed. São Paulo: Saraiva, 2011.

SILVEIRA, Renato de Mello Jorge. Direito Penal Supra-Individual: interesses difusos. São Paulo: Editora Revista dos Tribunais, 2003.

Resolução 217 A (III) da Assembléia Geral das Nações Unidas em 10 de dezembro de 1948. Declaração Universal dos Direitos Humanos. Disponível em http://portal.mj.gov.br/sedh/ct/legis_intern/ddh_ 
bib_inter_universal.htm, acesso em 24.05.2015.

http://www.justice.gouv.fr/histoire-et-patrimoine-10050/la-justice-dans-

lhistoire-10288/loeuvre-revolutionnaire-les-fondements-de-lajustice-actuelle-1 1909.html, acesso em 03.10.2015.

http://ledroitcriminel.free.fr/la_legislation_criminelle/anciens_textes/ code_delits_et_peines_1795/code_delits_et_peines_1795_1.htm, acesso em 03.10.2015.

http://www.archives.gov/exhibits/charters/declaration_transcript.html, acesso em 03.10.2015.

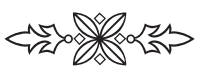

